\title{
Translating English Legal Lexical Features into Arabic: Challenges and Possibilities
}

\author{
Mahmoud Altarabin \\ Department of English, Faculty of Arts \\ Islamic University of Gaza, Gaza Strip, Palestine
}

\begin{abstract}
The challenges of legal translation between English and Arabic are not sufficiently investigated despite the impact such challenges can have on the translation product. There is a huge volume of translation between English and Arabic for legal texts such as contracts of various types, wills, articles of association, lawsuits, to name but a few. Notwithstanding the pitfalls of translation between English and Arabic in general, translating legal texts poses certain challenges of critical implications. Such challenges can be attributed to the difference in the structure of the legal texts, types of legal texts, and, most importantly, the difference in the legal system between the Arab countries on the one hand and the English-speaking countries on the other. The present paper aims to discuss the lack of uniformity in legal translation, differences within the same legal system and the translator's lack of familiarity with legal terms. It also aims to highlight certain challenges such as the contextual meaning and connotative meaning.
\end{abstract}

Keywords: connotation and denotation, different legal systems, familiarity, uniformity

Cite as: Altarabin, M. (2018). Translating English Legal Lexical Features into Arabic: Challenges and Possibilities. Arab World English Journal for Translation \& Literary Studies, 2 (2). DOI: http://dx.doi.org/10.24093/awejtls/vol2no2.14 